\title{
ANALYTICAL METHOD DEVELOPMENT AND VALIDATION OF AMLODIPINE IN HUMAN PLASMA USING LIQUID CHROMATOGRAPHY-MASS SPECTROMETRY/MASS SPECTROMETRY
}

\author{
AKIFUL HAQUE M*, SHANTHI PRIYA D K, DIBYALOCHAN MOHANTY, VASUDHA BAKSHI, \\ NARENDER BOGGULA
}

Department of Pharmaceutical Analysis, School of Pharmacy, Anurag Group of Institution, Venkatapur, Ghatkesar, Telangana, India. Email: akif963@gmail.com

Received: 23 February 2018, Revised and Accepted: 17 April 2018

ABSTRACT

Objective: The objective of the present investigation was to develop a novel, simple, and economic method for the estimation of amlodipine in positive ion mode in human plasma using amlodipine maleate $\mathrm{d} 4 \mathrm{as}$ an internal standard.

Methods: The chromatographic separation was performed on Zorbax SB, $\mathrm{C}_{18}, 50 \mathrm{~mm} * 4.6 \mathrm{~mm}$, and $3.5 \mathrm{~mm}$. The mobile phase was prepared with a mixture of $5 \mathrm{~mm}$ ammonium acetate in $0.1 \%$ formic acid: High performance liquid chromatographic (HPLC) grade methanol:HPLC grade acetonitrile (40:30:30) that run isocratically at the flow rate of $0.700 \mathrm{ml} / \mathrm{min}$ and run time at $2.50 \mathrm{~min}$.

Results: The analytical method is valid for the estimation of amlodipine, in human plasma over a range of $0.100 \mathrm{ng} / \mathrm{ml}-9.990 \mathrm{ng} / \mathrm{ml}$ with the detection of amlodipine m/z - 409.10 (parent) and 238.00 (product), and internal standard Amlodipine Maleate d4 m/z - 413.20 (parent), and 238.00 (product) in positive ion mode. The results of carryover test, matrix effect, linearity, precision and accuracy, stabilities, dilution integrity, and run size evaluation test presented in this report are within the acceptance range.

Conclusion: A sensitive method for the separation and determination of amlodipine in plasma has been developed based on solid-phase extraction with disposable extraction cartridges in combination with LC and mass spectrophotometers (MS/MS).

Keywords: Amlodipine, Amlodipine maleate d4, Liquid chromatography-mass spectrophotometers/mass spectrophotometers, Human plasma, Validation, Stability studies.

(C) 2018 The Authors. Published by Innovare Academic Sciences Pvt Ltd. This is an open access article under the CC BY license (http://creativecommons. org/licenses/by/4. 0/) DOI: http://dx.doi.org/10.22159/ajpcr.2018.v11i7.25431

\section{INTRODUCTION}

Amlodipine is a three-ethly-5-methly-2-[(2-aminoethoxy) methyl]-four-(2-chlorophenyl)6-methyl,1,4-dihydro pyridine3 ,five- dicarboxylate [1]. It is a calcium channel blocker that dilates (widens) blood vessels and improves blood waft. It's so far used to treat chest pain (angina) and different situations due to coronary artery illnesses. It is also used to treat excessive blood pressure. It is also used alone or together with other drug treatments to treat chest pain and high blood pressure. It affects the movement of calcium into the cells of the heart and blood vessels as amlodipine is a calcium antagonists it reduces coronary and peripheral vascular resistance, decreases blood pressure and myocardial oxygen intake. Amlodipine is norm frequent (with everyday heart rate) and has $24 \mathrm{~h}$ long impact. Chemical formulation of amlodipine is $\mathrm{C}_{20} \mathrm{H}_{25} \mathrm{ClN}_{2} \mathrm{O}_{5}$, molecular weight is 567.1 , and it is barely soluble in water and sparingly soluble in ethanol (Fig. 1) [5].

Amlodipine is a dihydropyridine derivative calcium antagonist (Calcium ion antagonist or slow channel blocker) that inhibits the transmembrane inflow of calcium ions into vascular smooth muscle and cardiac muscle. After oral management of therapeutic doses of amlodipine, absorption produces height plasma concentrations between 6 and $12 \mathrm{~h}$. Amlodipine is considerably (approximately 90\%) transformed to inactive metabolites through hepatic metabolism with $10 \%$ of the determined compound and $60 \%$ of the metabolites excreted in the urine. Amlodipine is slowly and nearly absolutely absorbed from the gastrointestinal tract [6]. Peak plasma attention is reached 6-12 h following oral management. Its predicted bio-availability is $64-90 \%$. Absorption is not stricken by meals.

Inner standard decided on for the estimation of amlodipine is amlodipine maleate d4 (Fig. 2).

\section{METHODS}

Amlodipine and Amlodipine maleate $\mathrm{d} 4$ have been procured from Vivan Life Technology Pvt. Ltd., acetonitrile (high performance liquid chromatographic [HPLC] grade), ammonium acetate and formic acid were obtained from Merck and methanol (HPLC grade) is from JT Baker. The water was purified using Milli-Q device (Rankem).

Calibration curve requirements and quality control samples Calibration curve trendy together with a set of 9 non-zero concentrations ranging from $0.100 \mathrm{ng} / \mathrm{ml}$ to $9.990 \mathrm{ng} / \mathrm{ml}$ of amlodipine were organized. Organized high-quality manage samples consisted of concentrations of $0.101 \mathrm{ng} / \mathrm{ml}$ (lloq quality control), $0.287 \mathrm{ng} / \mathrm{ml}$ (lqc), $1.198 \mathrm{ng} / \mathrm{ml}$ (mqc1), $4.991 \mathrm{ng} / \mathrm{ml}$ (mqc2), and $7.799 \mathrm{ng} / \mathrm{ml}$ (hqc) for amlodipine. Those samples have been saved at $-70^{\circ} \mathrm{C}$ until use.

\section{Optimized bioanalytical conditions (Table 1)}

Sample preparation

The samples were thawed at room temperature and vortexed to make certain entire blending of the contents. $300 \mu \mathrm{l}$ of the plasma sample was pipetted $5 \mathrm{ml}$ polypropylene ria vial tubes, $30 \mu \mathrm{l}$ of internal standard dilution (49.985 $\mathrm{ng} / \mathrm{ml}$ of amlodipine maleate $\mathrm{d} 4$ ) became delivered to it and vortexed, besides in blank plasma samples where $30 \mu \mathrm{l}$ diluent was introduced and vortexed. Then, $500 \mu \mathrm{l}$ of HPLC grade water turned into introduced and vortex. The sample aggregate was loaded onto strata $\times 33 \mu \mathrm{m}$ polymeric sorbent $(30 \mathrm{mg} / 1 \mathrm{cc}$ ) cartridges that have been pre-conditioned with $1.0 \mathrm{ml}$ of HPLC grade methanol followed through $1.0 \mathrm{ml}$ Milli-Q/HPLC grade water (new cartridge for each pattern). After making use of the most pressure, the extraction cartridge becomes washed with $1 \mathrm{ml}$ of $50 \mathrm{~mm}$ ammonium acetate and $2 \mathrm{ml}$ of Milli-Q/HPLC grade water ( $1 \mathrm{ml}$ every time). Then, the samples 
were eluted with $2 \mathrm{ml}$ of methanol and evaporated to dryness at $45^{\circ} \mathrm{C}$ beneath gentle movement of nitrogen and the dried extract changed into reconstituted with $300 \mu \mathrm{l}$ of the cellular segment. The samples had been transferred to sampler loading vials (ambered coloration) and loaded.

\section{Validation}

Method validation consists of all of the techniques required to demonstrate that a method to quantify the attention of amlodipine in plasma is dependable for the intended software.

\section{Carry overcheck}

Certainly organized extracted matric clean (cot clean), excessive (cot uloq), and low (lloq) attention of analyte while injected, the effects display that there is no deliver over the impact of the analyte and internal preferred. Fig. 3 is the representative chromatogram of extracted blank plasma sample analyzed for carryover test.

Accuracy and precision (Tables 2-4)

Inside-batch, intraday, and between-run/interday precision and accuracy have been evaluated at three nice control samples concentrations (lqc, mqc1, mqc2, and hqc). Inside-batch, intraday, and between-run/interday assay precision was determined as coefficient of variation \%, and within-batch, intraday, and between-run/ interdayassay accuracies have been expressed as percent nominal.

\section{Linearity}

Use a regression equation with the perfect weighting thing for determining the detector reaction/concentration courting. Encompass trendy and widespread in training of calibration curve. Fig. 4 suggests representative calibration curve for regression evaluation of

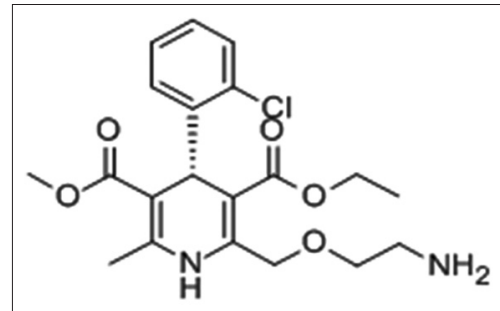

Fig. 1: Structure of amlodipine [1]

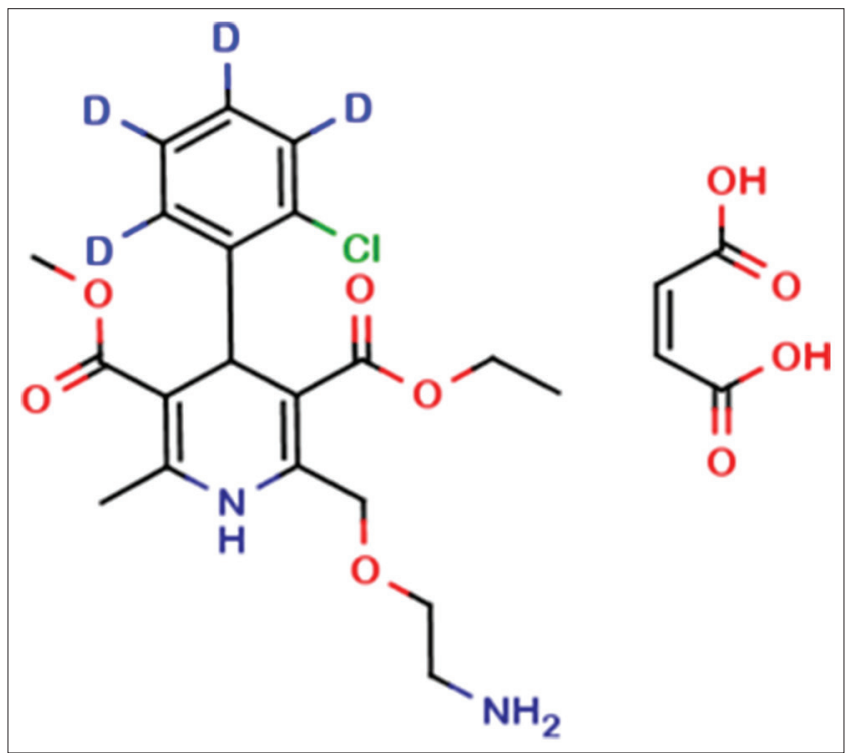

Fig. 2: Structure of amlodipine maleate d4 [10] amlodipine.

\section{Sensitivity (Table 5)}

Decide the sensitivity in phrases of lloq in which the reaction of the lloq need to be at least 5 times greater than the reaction of interference in a clean matrix on the retention time or mass transitions of the analyte(s).

\section{Dilution integrity (Table 6)}

Put together 12 units of qcs spiked with approximately 1.5-1. Eight instances the concentration of the highest preferred (uloq) method six units of above qcs with the aid of diluting them 2 times and another six sets using diluting four instances before extraction by addition of screened blank matrix. Inject these quality control samples along with the calibration curve requirements processed without dilution and calculate the quality control concentrations using multiplication issue as 2 (for 2 times diluted samples) and four (for 4 times diluted samples).

\section{Stabilities}

Freeze and thaw stability (Table 7)

The samples have been saved at $-20^{\circ} \mathrm{C}$ and thawed at room temperature $\left(\leq 27^{\circ} \mathrm{C}\right)$. The stability of quality controls concentrations was envisioned after three cycles of freezing and thawing of samples. The samples have been analyzed underneath a fresh calibration curve and the concentrations obtained have been as compared with the nominal attention of exceptional manage samples.

\section{Re-injection stability (Table 8)}

In having access to the reinjection balance, six sets of quality control samples (lqc and hqc) had been processed and analyzed with calibration curve general. The qc samples have been retained within the vehicle sampler and re-injected after a period of $46 \mathrm{~h} 30 \mathrm{~min}$ and quantified in opposition to the preliminary calibration curve statistics. The mean concentration of re-injected qcs becomes in comparison against the imply of the qcs while injected for $1^{\text {st }}$ time.

\section{Wet extract stability (Table 9)}

Moist extract balance is finished to evaluate the integrity of analyze samples which had been kept at room temperature over a time period after processing. Good enough wide variety of low and excessive quality control samples ( 6 replicates) to facilitate injection at proposed balance durations. Maintain the processed samples in vehicle sampler at room temperature/special temperature. At the day of balance, put together sparkling trendy inventory solution of analyte(s). Inject quality controls samples in replicates (6 samples each) in conjunction with the freshly spiked calibration standards of awareness variety equal to that used for the calculation of precision and accuracy. Calculate the autosampler stability intervals at the time of injection of first quality control; much less the sample training completed time.

Autosampler stability (Table 10)

Autosampler stability of the analyte and inner widespread is done at a selected temperature for the time frame relying at the anticipated run time for the whole evaluation of a batch length. Number of low and excessive quality controls samples ( 6 replicates) is facilitated to inject at proposed stability durations, hold the processed samples at room temperature. On the day of stability, inject qc samples in replicates ( 6 samples every) along with the freshly spiked calibration requirements of concentration range equal to that used for the calculation of precision and accuracy.

\section{RESULTS}

Carryover test

Precision and accuracy

Linearity

Sensitivity

Dilution integrity

Stabilities 


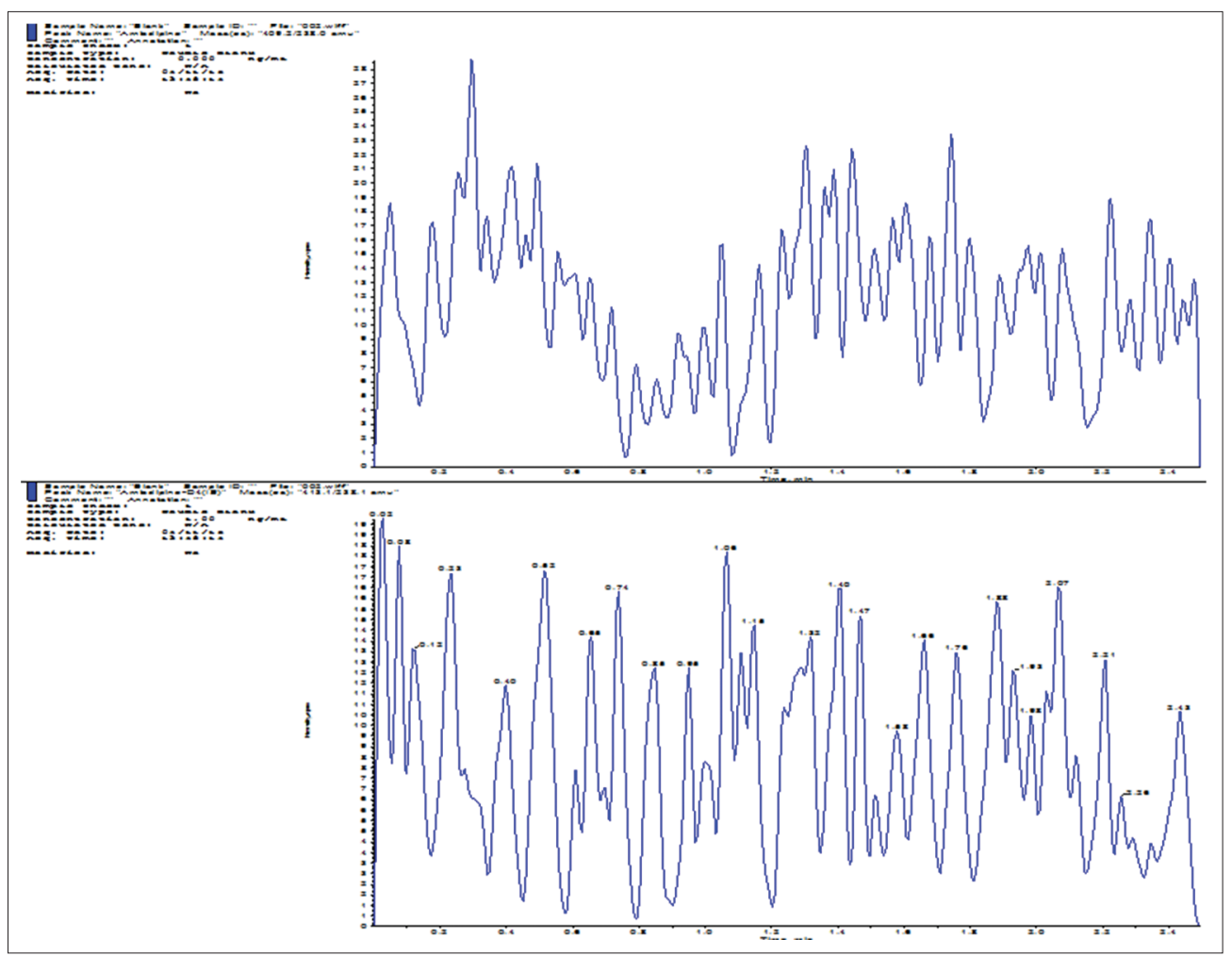

Fig. 3: Representative chromatogram of blank plasma sample of amlodipine

Table 1: Optimized chromatographic conditions

\begin{tabular}{ll}
\hline Chromatographic conditions & \\
\hline Column & $\begin{array}{l}\text { Zorbax SB, C18, } 50 \mathrm{~mm} * 4.6 \mathrm{~mm}, \\
\text { and } 3.5 \mu \mathrm{m}\end{array}$ \\
& $5 \mathrm{~mm}$ ammonium acetate in \\
& $0.1 \%$ formic acid: methanol: \\
Mobile phase & acetonitrile $(30: 30: 40$ ) \\
& Acetonitrile: Milli- $Q$ water $(60: 40)$ \\
& $0.7 \mathrm{~mL} / \mathrm{min}$ \\
Rinsing solution & $10^{\circ} \mathrm{C}$ \\
Flow rate & $20 \mu \mathrm{L}$ \\
Sampler cooler temperature & $50: 50$ \\
Injection volume & $1000 \mu \mathrm{L}$ \\
Split ratio & $1.35 \pm 0.5$ (amlodipine) \\
Needle rinsing volume & $1.35 \pm 0.5$ (amlodipine maleate $\mathrm{d} 4$ ) \\
Retention times & $2.50 \mathrm{~min}$ \\
\hline
\end{tabular}

Table 2: Within, batch precision and accuracy for analysis of amlodipine in human plasma

\begin{tabular}{llll}
\hline $\begin{array}{l}\text { Nominal } \\
\text { concentration }\end{array}$ & Within batch & & \\
\hline $\mathbf{n g} / \mathbf{m l}$ & Mean \pm SD & Accuracy (\%) & CV (\%) \\
\hline LQC $(0.28 \mathrm{ng} / \mathrm{ml})$ & $0.26 \pm 0.01$ & 91.35 & 7.61 \\
MQC1 $(1.1 \mathrm{ng} / \mathrm{ml})$ & $1.11 \pm 0.007$ & 93.36 & 0.69 \\
MQC2 $(4.9 \mathrm{ng} / \mathrm{ml})$ & $4.97 \pm 0.05$ & 99.65 & 1.01 \\
HQC $(7.7 \mathrm{ng} / \mathrm{ml})$ & $7.37 \pm 0.11$ & 94.62 & 1.55 \\
\hline
\end{tabular}

SD: Standard deviation, CV: Coefficient of variation

\section{DISCUSSIONS}

The chromatographic method was optimized by changing various parameters, such as $\mathrm{PH}$ of the mobile phase, organic modifier, and buffer used in the mobile phase. Under the presently prescribed conditions, it
Table 3: Intraday precision and accuracy for analysis of amlodipine in human plasma

\begin{tabular}{llll}
\hline $\begin{array}{l}\text { Nominal } \\
\text { concentration }\end{array}$ & Intra batch & & \\
\hline $\mathbf{n g} / \mathbf{m l}$ & Mean \pm SD & Accuracy (\%) & CV (\%) \\
\hline $\mathrm{LQC}(0.28 \mathrm{ng} / \mathrm{ml})$ & $0.28 \pm 0.02$ & 100.03 & 10.35 \\
MQC1 $(1.1 \mathrm{ng} / \mathrm{ml})$ & $1.11 \pm 0.01$ & 93.12 & 1.00 \\
MQC2 $(4.9 \mathrm{ng} / \mathrm{ml})$ & $4.96 \pm 0.04$ & 99.39 & 0.86 \\
HQC $(7.7 \mathrm{ng} / \mathrm{ml})$ & $7.36 \pm 0.08$ & 94.44 & 1.21 \\
\hline
\end{tabular}

SD: Standard deviation, CV: Coefficient of variation

Table 4: Interday precision and accuracy for analysis of amlodipine in human plasma

\begin{tabular}{llll}
\hline $\begin{array}{l}\text { Nominal } \\
\text { concentration }\end{array}$ & Inter-batch & & \\
\hline $\mathbf{n g} / \mathbf{m l}$ & Mean士SD & Accuracy (\%) & CV (\%) \\
\hline LQC $(0.28 \mathrm{ng} / \mathrm{ml})$ & $0.29 \pm 0.02$ & 103.79 & 6.95 \\
MQC1 $(1.1 \mathrm{ng} / \mathrm{ml})$ & $1.11 \pm 0.01$ & 93.03 & 1.16 \\
MQC2 $(4.9 \mathrm{ng} / \mathrm{ml})$ & $4.95 \pm 0.04$ & 99.19 & 0.86 \\
HQC $(7.7 \mathrm{ng} / \mathrm{ml})$ & $7.35 \pm 0.08$ & 94.26 & 1.12 \\
\hline
\end{tabular}

SD: Standard deviation, $\mathrm{CV}$ : Coefficient of variation

was found that there was no carryover test in the proposed method. Representative chromatogram is shown in Fig. 3. Hence, this method is very useful for determination of amlodipine in the pharmaceutical dosage form. It was also found that the differences of $<5.0 \%$ for within, intra- and inter-day data reflect the precision of the method. The observation of percentage $\mathrm{CV}<10$ for within, intra- and inter-day measurements also indicates a high degree of precision. The results of accuracy and precision are shown in Tables 2-4. In this study, the developed chromatographic method the linearity ranges from 0.100 $\eta \mathrm{g} / \mathrm{ml}$ to $9.990 \mathrm{\eta g} / \mathrm{ml}$. The regression curve of amlodipine is shown 


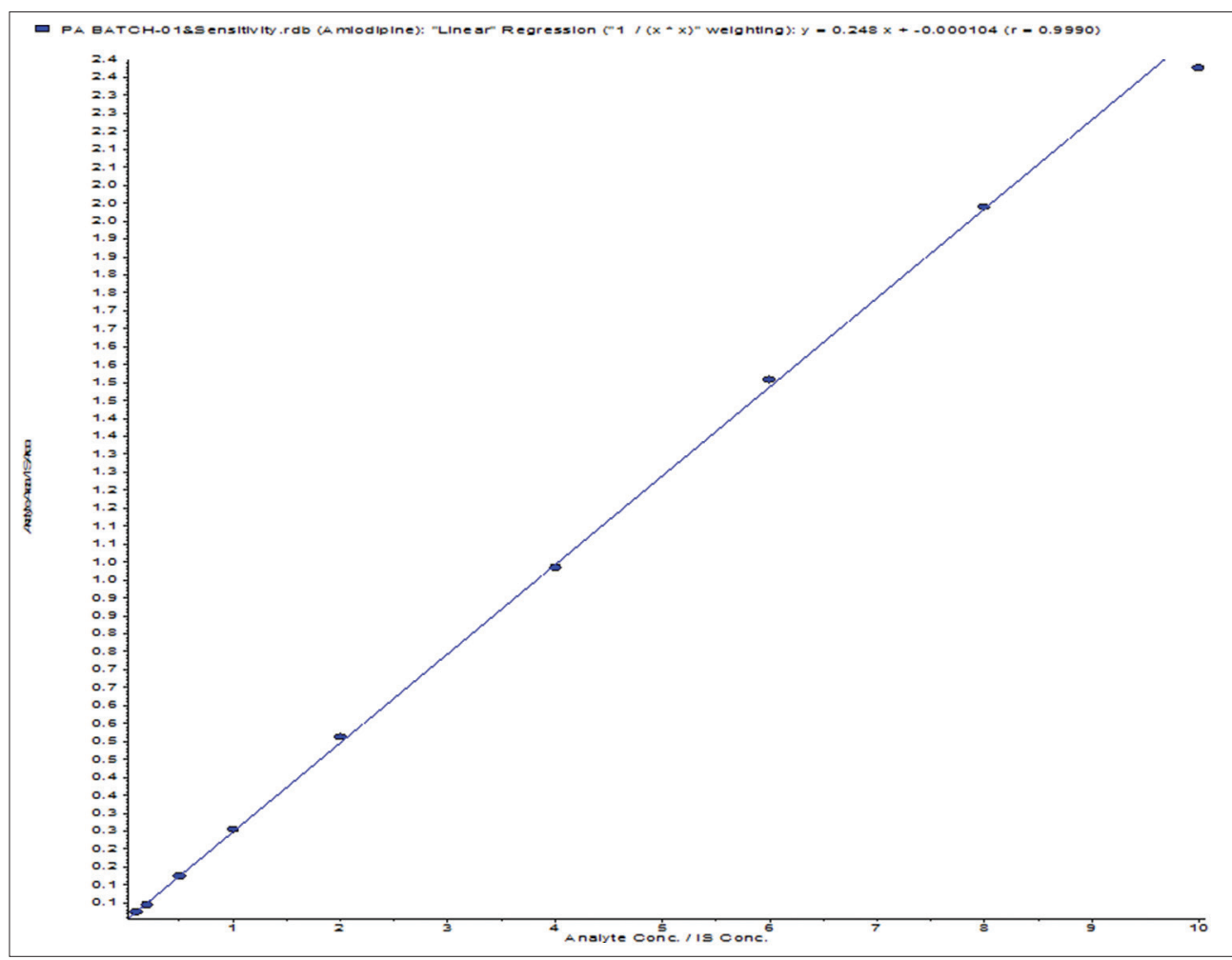

Fig. 4: A representative calibration curve for regression analysis of amlodipine

Table 5: Within batch precision and accuracy for the sensitivity of amlodipine

\begin{tabular}{llll}
\hline QC level & Mean \pm SD & \% CV & \% Accuracy \\
\hline LLOQ & $0.099 \pm 0.004$ & 4.13 & 99.83 \\
\hline
\end{tabular}

SD: Standard deviation, CV: Coefficient of variation

Table 6: Dilution integrity data for amlodipine (20 times and 4 times)

\begin{tabular}{llll}
\hline Dilution factor & Mean \pm SD & \% CV & \% Accuracy \\
\hline $1 / 2$ & $17.0 \pm 0.06$ & 0.04 & 105.67 \\
$1 / 4$ & $34.1 \pm 0.19$ & 0.57 & 105.81 \\
\hline
\end{tabular}

SD: Standard deviation, CV: Coefficient of variation

Table 7: Stability data for free-thaw stability

\begin{tabular}{lllllll}
\hline Analyte (amlodipine) & LQC (\%) & & & \multicolumn{2}{l}{ HQC (\%) } & \\
\cline { 2 - 3 } & Nominal & CV & & Nominal & CV \\
\hline Freeze-thaw stability & 107.74 & 1.48 & & 96.14 & 0.86 \\
\hline CV: Coefficient of variation & & & &
\end{tabular}

in Fig. 4. The sensitivity results gave good recovery and results are shown in Table 5 due to high sensitivity, the method was used to detect the drug in different stabilities studies. The different stabilities were performed at different suitable conditions, and their results were within acceptance criteria, and their results are represented in Tables 7-10.

\section{CONCLUSION}

In summary, a enormously, unique, reproducible, and highthroughput LC-mass spectrophotometers (MS)/MS approach become advanced and tested based on the procedure of solid-phase extraction for quantification of Amlodipine pharmacokinetic and bioequivalence research. The extraction manner and LC-MS/MS
Table 8: Stability data for re-injection stability

\begin{tabular}{llllll}
\hline Analyte (amlodipine) & LQC (\%) & & & HQC (\%) & \\
\cline { 2 - 3 } \cline { 5 - 6 } & Nominal & CV & & Nominal & CV \\
\hline $\begin{array}{lllll}\text { Re-injection stability } \\
\text { (46 h-30 min) }\end{array}$ & 107.61 & 2.29 & & 94.46 & 0.46 \\
\hline CV: Coefficient of variation & & & & \\
\hline
\end{tabular}

Table 9: Stability data for wet extract stability

\begin{tabular}{llllll}
\hline Analyte (amlodipine) & LQC (\%) & & & HQC & \\
\cline { 2 - 3 } \cline { 5 - 6 } & Nominal & CV & & Nominal & CV \\
\hline $\begin{array}{l}\text { Wet extract stability } \\
\text { (69 h-50 min) }\end{array}$ & 105.92 & 2.12 & & $98.87 \%$ & 1.02 \\
\hline CV: Coefficient of variation & & & & \\
\hline
\end{tabular}

Table 10: Stability data for autosampler stability

\begin{tabular}{llllll}
\hline Analyte (amlodipine) & LQC (\%) & & & HQC (\%) & \\
\cline { 2 - 3 } \cline { 5 - 6 } & Nominal & CV & & Nominal & CV \\
\hline $\begin{array}{l}\text { Autosampler stability } \\
\text { (74 h-25 min) }\end{array}$ & 105.05 & 1.25 & & 94.44 & 2.70 \\
\hline
\end{tabular}

conditions have been optimized to be able to enhance the sensitivity and robustness of the technique. In the end, the technique turned into completely tested to fulfill the necessities for sensitivity, accuracy, and precision defined through kingdom food and drug administration and GLP guidelines.

From the optical characteristics, of the proposed method, it changed into determined that the results of sensitivity, carryover test, linearity, precision accuracy, and stabilities provided in this article are in the recognition range, and the analytical approach which is defined above 
is legitimate for the estimation of amlodipine, in human plasma over various $0.100 \mathrm{\eta g} / \mathrm{ml}-9.990 \mathrm{\eta g} / \mathrm{ml}$ with the detection of amlodipine $\mathrm{m} / \mathrm{z}-409.10$ (parent) and 238.00 (product) and internal amlodipine maleate $\mathrm{d} 4 \mathrm{~m} / \mathrm{z}-413.20$ (parent) and 238.00 (product) in positive ion mode. A summary of the validation parameters and the effects are provided above.

\section{ACKNOWLEDGMENT}

The facility provided for the authors to work at Anacipher Clinical Research Organization and Anurag Group of Institutions is highly acknowledged for presenting all the vital centers to carry out this studies work

\section{AUTHORS' CONTRIBUTION}

All the authors contributed equally.

\section{CONFLICTS OF INTEREST}

Declared none.

\section{REFERENCES}

1. Available from: http://www.wikipedia.org/wiki/Amlodipine

2. Gohil K, Trivedi P, Molvi KI. Spectrophotometric analysis of amlodipine besylate in bulk and in tablet dosage forms. Indian J Pharm Sci 2005;67:376.
3. Bhatt J, Singh S, Subbaiah G, Shah B, Kambli S, Ameta S. A rapid and sensitive liquid chromatography-tandem mass spectrometry (LCMS/MS) method for the estimation of amlodipine in human plasma. Biomed Chromatogr 2007;21:169-75

4. Macek J, Klíma J, Ptácek P. A rapid determination of valsorton and amlodipine in human plasma by protein precipitation and high performance liquid chromatography. J Chromatogr B Analyt Technol Biomed Life Sci 2006;832:169-72.

5. Rahman N, Azmi SN. 'Spectrophotometric method for the determination of amlodipine besylate with ninhydrin in drug formulations. Farmaco 2001;56:731-5.

6. Zarghi A, Foroutan SM, Shafaati A, Khoddam A. Validated HPLC method for determination of amlodipine in human plasma and its application to pharmacokinetic studies. Farmaco 2005;60:789-92.

7. Rao JR, Kadam SS, Mahadik KR. Methods of estimation of multicomponent formulations: A review. Indian Drugs 2002;39:378-81.

8. González L, López JA, Alonso RM, Jiménez RM. Fast screening method for the determination of angiotensin|। receptor antagonists in human plasma by high performance liquid chromatography with flourimetric detection'. J Chromatogr A 2002;9499:49-60.

9. Philipp T, Smith TR, Glazer R, Wernsing M, Yen J, Jin J, et al. Two multicenter, 8-week, randomized, double-blind, placebo-controlled, parellel-group studies evaluating the efficacy and tolerability of amlodipine and valsarton in combination and as monotherapy in adult patients with mild to moderate essential hypertension. Clin Ther 2007;29:563-80

10. Available from: https://www.pubchem.ncbi.nlm.nih.gov. 